Ann. Biol. anim. Bioch. Biophys., 1979, 19 (3 B), 937-942.

\title{
Etude in vitro du comportement des populations microbiennes du rumen en présence de zinc sous forme de sulfate
}

\author{
par Annie BONHOMME, Michelle DURAND *, Christiane DUMAY * \\ P. BEAUMATIN * \\ Laboratoire de Zoologie, U.E.R. des Sciences, \\ B.P. 34751062 Reims Cedex \\ * Station de Recherches de Nutrition, I.N.R.A., \\ 78350 Jouy-en-Josas
}

Summary. «In vitro » study of the influence of zinc on rumen microbial populations.

The effects of different zinc sulfate levels on the metabolism of rumen microorganisms and on the growth of protozoan cultures were studied in vitro. Ciliate uptake of zinc was observed by electron microscopy and by electron microprobe microanalysis. Bacteria cellulolytic activity, unimproved by the addition of a small quantity of $\mathrm{Zn}$, was significantly reduced by a zinc level of $10 \mu \mathrm{g} / \mathrm{ml}$ in the incubation medium. Bacterial proteosynthesis, estimated by ammonia utilization, was unmodified, even at a zinc level of $25 \mu \mathrm{g} / \mathrm{ml}$. An inhibitory effect of high zinc levels on urease was significant only when bacterial cells were disrupted. 5 to $10 \mu \mathrm{g} / \mathrm{ml}$ zinc stimulated protozoan growth of the genus Entodinium. The rate of cellular division increased after each addition of zinc. At $25 \mu \mathrm{g} / \mathrm{ml}$, zinc induced a decrease of the population after 9 days of culture, whereas « granules 》 were already observed in the ciliate endoplasm after 20 hours; at $500 \mu \mathrm{g} / \mathrm{ml}$, the zinc penetrated the cells heavily. Using microanalysis, the $X$ emission recording showed $K \alpha_{1}$ and $K \alpha_{2}$ lines of zinc in Entodinium and Polyplastron ciliates from zinc levels of 2.5 to $25 \mu \mathrm{g} / \mathrm{ml}$; zinc uptake was greater at the higher concentration. Under these experimental conditions, zinc affected rumen microbial populations differently. Protozoa incorporated zinc easily and were intolerant of high zinc levels. However, zinc did not seem to penetrate the bacterial cells readily, and at high concentrations inhibited metabolic activities only when the enzymes were extracellular or free in the medium after microbial lysis.

\section{Introduction.}

La multiplicité des fonctions moléculaires ef cellulaires du zinc a été mise en évidence ces dernières années. Cet élément qui revêt un rôle important dans la division cellulaire est susceptible d'influencer le métabolisme de la micropopulation du rumen. Les bactéries concentreraient le zinc (Kumaresan, 1976), mais son influence sur leur métabolisme est encore controversée. Les résultats concernant les protozoaires sont limités à l'effet de concentrations élevées de zinc sur leur activité fermentaire (Uesaka, Kawashima et Zembayashi, 1966). 


\section{Matériel et méthodes.}

\section{Métabolisme de la micropopulation du rumen.}

Des incubations in vitro sont effectuées en présence de doses croissantes de zinc: 1 , $5,10,25 \mu \mathrm{g} / \mathrm{ml}$ de milieu, doses correspondant à des taux de zinc de l'aliment de 60 , 200,400 et $1000 \mathrm{mg} / \mathrm{kg}$. L'inoculum est prélevé sur six moutons adultes munis d'une canule de rumen qui reçoivent $800 \mathrm{~g}$ par jour d'aliment semi-purifié contenant de l'urée (4 p. 100) comme seule source d'azote. L'activité cellulolytique a été estimée en mesurant la dégradation de la cellulose de l'aliment au cours d'incubations de $24 \mathrm{~h}$ en présence de jus de rumen filtré et de salive artificielle. La dégradarion de l'urée et l'utilisation de l'ammoniaque par les microorganismes sont mesurées (selon Kumaresan, 1976) au cours d'incubations d'une durée de $5 \mathrm{~h}$, réalisées avec du contenu total de rumen dilué avec un volume égal de salive artificielle, en utilisant l'aliment à 10 ppm de zinc comme substrat de base. L'utilisation de l'ammoniaque dans nos conditions expérimentales (substrat sans protéine) représente approximativement la protéosynthèse microbienne. De plus, nous avons comparé l'effet de doses supérieures de zinc $(15,35$ ou $180 \mathrm{mg} / \mathrm{l})$ sur l'activité uréasique d'une suspension lavée de microorganismes soit infacte, soit broyée. Du jus de panse filtré était centrifugé $20 \mathrm{mn}$ à $20000 \mathrm{~g}$. Le culot lavé était repris dans la salive artificielle, une partie aliquote était broyée 5 min à $4^{\circ} \mathrm{C}$ dans un appareil «Vibrogen » avec des microbilles de verre et diluée dans un volume de salive égal au volume de départ. La dégradation de l'urée (1 $\mathrm{mg} / \mathrm{ml}$ de milieu) était mesurée dans les mêmes conditions avec la suspension de cellules entières ou broyées, durant $3 \mathrm{~h}$ d'incubation.

\section{Croissance des protozoaires ef incorporation du zinc.}

L'effet in vitro de concentrations croissantes de zinc $(1,5 ; 2,5 ; 5 ; 10$ et $25 \mu \mathrm{g} / \mathrm{ml})$ est testé sur la croissance des ciliés. La technique de culture est celle de Coleman (1971); $\mathrm{ZnSO}_{4}$ est régulièrement ajouté tous les 3-4 jours. La population suivie en culture est celle des Entodinium, car ces ciliés sont les plus représentés. L'observation de la population ciliaire s'est déroulée en deux temps : du 1 er au $12^{\mathrm{e}}$ jour, puis lorsque la culfure est bien établie, du $22^{\mathrm{e}}$ au $36^{\mathrm{e}}$ jour.

La pénétration du zinc dans les ciliés incubés pendant $20 \mathrm{~h}$ au taux de $25 \mu \mathrm{g} / \mathrm{ml}$ ef pendant $2 \mathrm{~h}$ au taux de $500 \mu \mathrm{g} / \mathrm{ml}$ est étudiée en microscopie électronique. La microanalyse par sonde électronique (microsonde MS 46 et cristal analyseur LIF) est réalisée sur des étalements sur lames de terphane de ciliés. Ceux-ci sont préalablement incubés en présence de zinc au taux de 1,5 à $25 \mu \mathrm{g} / \mathrm{ml}$ et fixés à l'alcool.

\section{Résultats.}

1. Influence du zinc sur certains aspects du métabolisme de la micropopulation. Nous n'observons pas d'effet stimulant du zinc sur la cellulolyse ; par contre, l'effet inhibiteur du zinc est significatif dès le taux de $10 \mu \mathrm{g} / \mathrm{ml}$ ef particulièrement accentué au taux de $25 \mu \mathrm{g} / \mathrm{ml}$ (fig. 1). 
L'activité uréolytique ef l'utilisation de l'ammoniaque mesurées pendant $5 \mathrm{~h}$ d'incubation ne sont pas modifiées par l'apport de zinc même au taux le plus élevé. L'activité uréolytique des suspensions lavées de bactéries n'est inhibée significative-

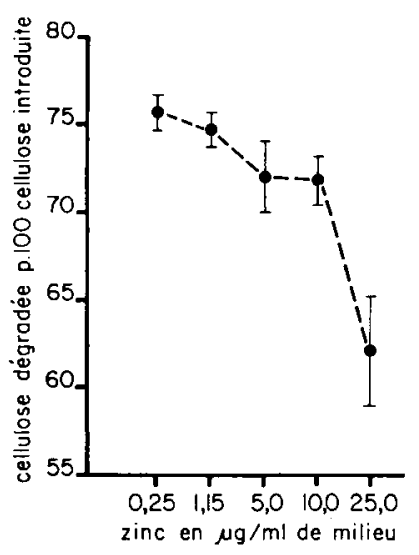

FIG. 1. - Effet de l'addition de zinc sur to cellulolyse in vitro.

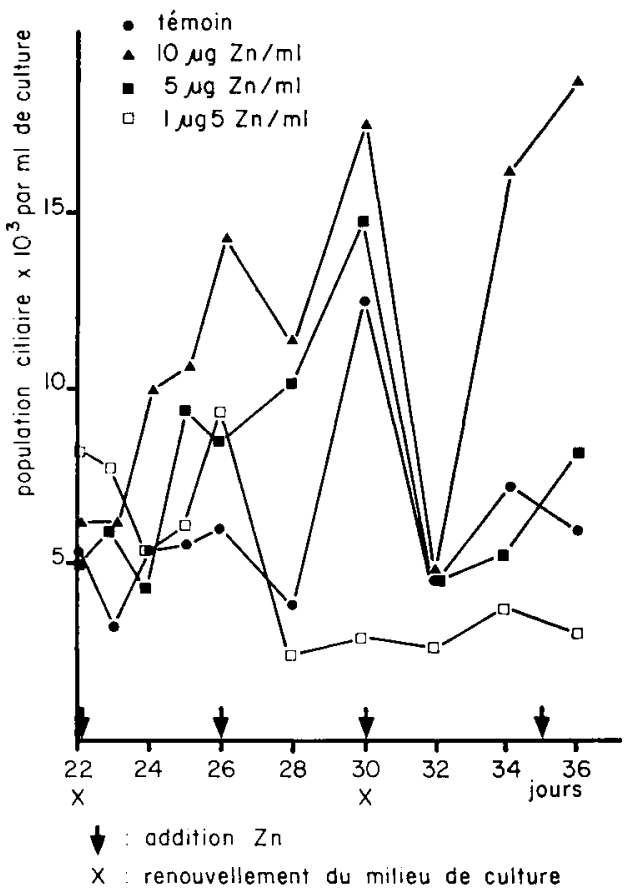

FIG. 3. - Croissance des ciliés entodinium en fonction des concentrations en zinc du milieu pendant la deuxième période de la culfure.

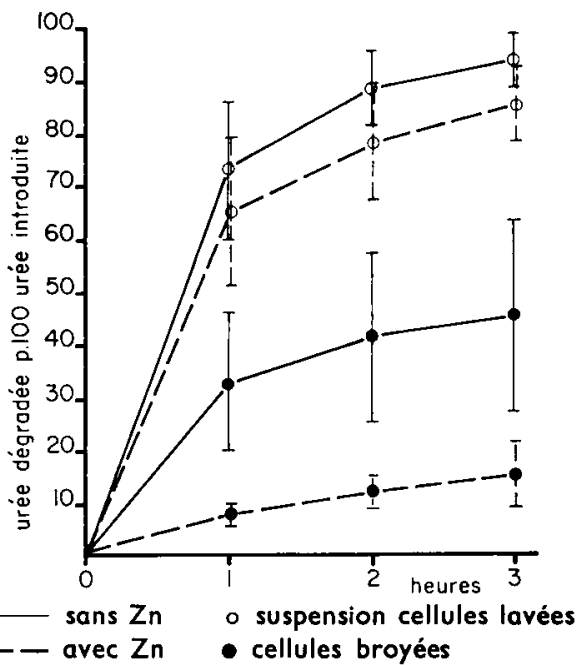

FIG. 2. - Effel du zinc $(180 \mu \mathrm{g} / \mathrm{ml})$ sur l'uréolyse.

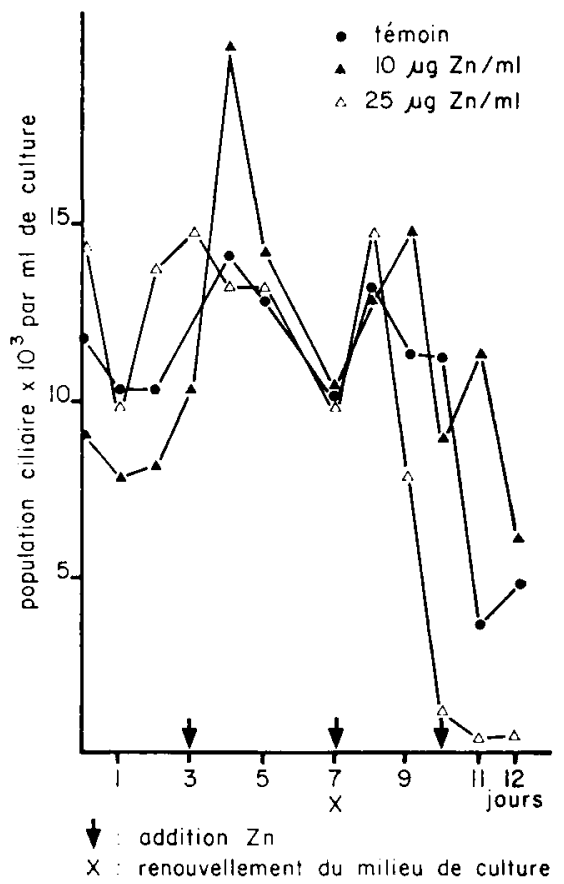

FIG. 4. - Variations des cilies entodinium en foncfion de la concentration en zinc du milieu pendant la première période de la culture. 
ment par les doses élevées de zinc que lorsque les suspensions sont broyées ; cet effet déjà important aux doses de 15 et $35 \mu \mathrm{g} / \mathrm{ml}$ est plus accentué et hautement significatif à la dose de $180 \mu \mathrm{g} / \mathrm{ml}$ (fig. 2).

2. Influence du zinc sur la croissance des protozoaires. - Les concentrations de 5 à $10 \mu \mathrm{g} / \mathrm{ml}$ sont favorables à la croissance des Entodinium par rapport au témoin (fig. 3 ). Les ciliés ne se déforment pas et se divisent régulièrement. Après chaque addition de zinc, on note une stimulation des divisions. A $25 \mu \mathrm{g} / \mathrm{ml}$ de zinc, on note, vers le 9 e jour de la culture, une chute rapide de la population qui disparaît le 4 e jour (fig. 4).

A des doses plus élevées, en $24 \mathrm{~h}$ à $500 \mu \mathrm{g} / \mathrm{ml}$ seuls les Isotriches survivent et à $1000 \mu \mathrm{g} / \mathrm{ml}$ les ciliés disparaissent totalement.

3. Incorporation du zinc dans les protozoaires. - Avec $25 \mu \mathrm{g} / \mathrm{ml}$ de zinc, on observe des cristaux dans l'endoplasme des ciliés, mais la pénétration est plus lente ef moins importante qu'avec $500 \mu \mathrm{g} / \mathrm{ml}$ (fig. 5). Les cristaux sont rarement envacuolés. En micro-

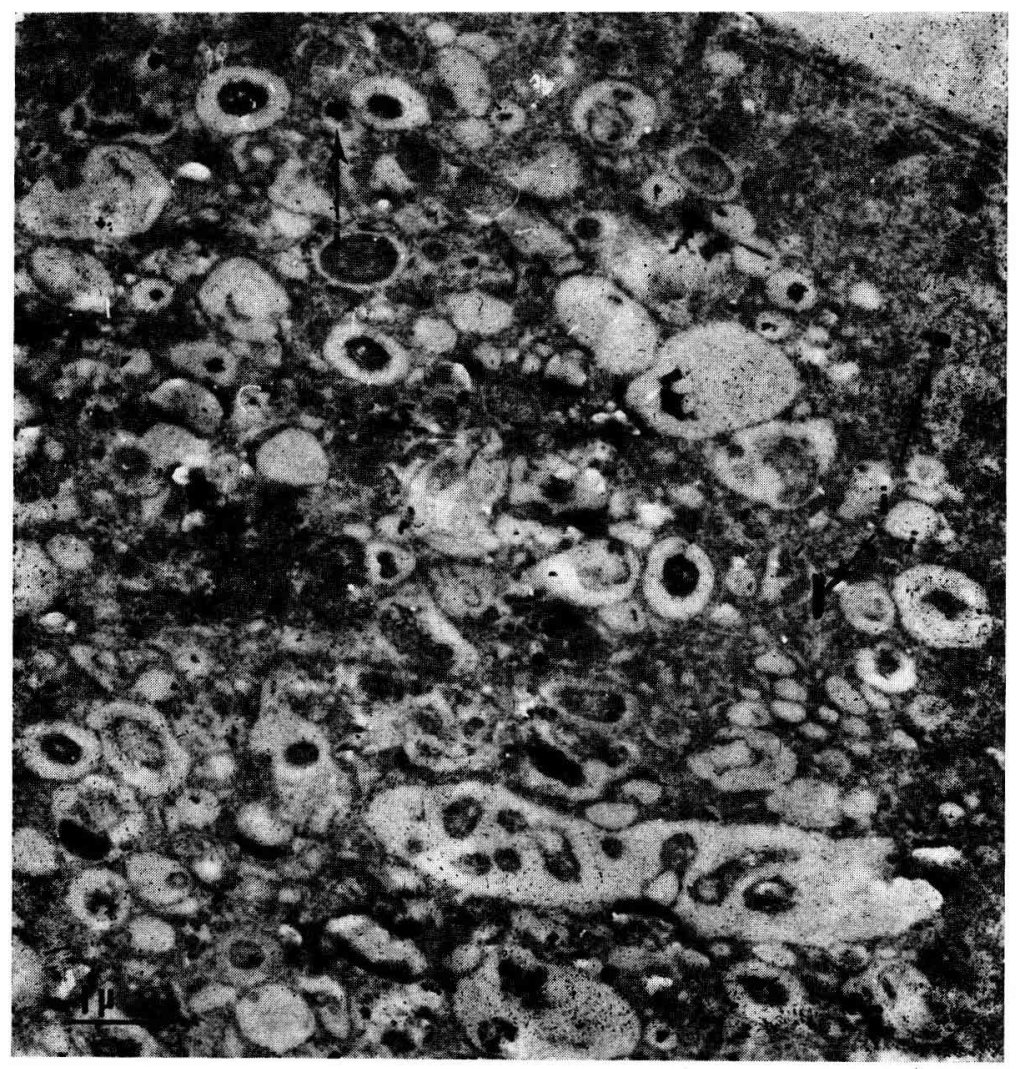

FIG. 5. $\rightarrow=$ Inclusion de zinc dans l'endoplasme d'un cilié (coupe non colorée).

analyse, l'enregistrement de l'émission $X$ fait apparaître les raies $K \alpha_{1}$ et $K \alpha_{2}$ du zinc, présent dans les ciliés des genres Entodinium et Polyplastron à partir de la concentration $2,5 \mu \mathrm{g} / \mathrm{ml}$ (fig. 6). Le genre Polyplastron semble concentrer davantage le zinc que le 
genre Entodinium. La proportion de ciliés ayant incorporé du zinc semble varier avec le taux de zinc du milieu ( 9 p. 100 d'Entodinium à $2,5 \mu \mathrm{g} / \mathrm{ml}$ et $15 \mathrm{p} .100 \mathrm{à} 10 \mu \mathrm{g} / \mathrm{ml}$ de zinc). nombre de
coups/sec
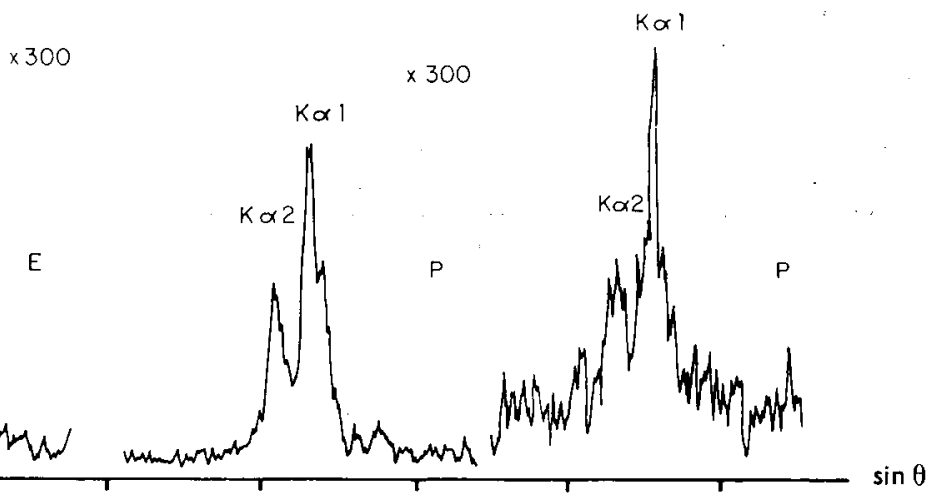

FIG. 6. - Enregistrement de l'émission $X$ (Raies $K \alpha_{1}$ et $K \alpha_{1}$ du zinc)

$(2,5 \mu \mathrm{g} / \mathrm{ml} \mathrm{Zn} 20 \mathrm{~h}) \mathrm{E}$ : Entodinium ; P : Polyplastron.

\section{Discussion.}

Dans nos conditions expérimentales, une différence dans le comportement des micropopulations du rumen en présence de zinc est mise en évidence. Un apport de zinc inférieur à $25 \mu \mathrm{g} / \mathrm{ml}$ stimule la croissance des protozoaires, mais n'active ni l'incorporation d'azote par les bactéries, ni leur activité cellulolytique. Failla (1977) note que le besoin en zinc des bactéries est dix fois plus faible que celui des algues ou des champignons.

Le zinc à dose élevée n'inhibe pas la protéosynthèse bactérienne et ne joverait un rôle répressif sur les activités enzymatiques bactériennes que lorsque les enzymes sont extracellulaires ou libérées dans le milieu après broyage ou lyse bactérienne. Le zinc pénétrerait donc difficilement dans la cellule bactérienne et resterait lié à la paroi cellulaire comme l'indique également Failla (1977). De plus, nos observations et les tests de microanalyse, en microscopie électronique, n'ont pratiquement pas révélé la présence du zinc dans les bactéries (résultats non publiés). Par contre, le zinc est facilement absorbé dans l'endoplasme des protozoaires où il se concentre sous forme de dépôts cristallins, ef ces microorganismes sont sensibles aux concentrations élevées.

Commission CNERNA Digestion-Absorption/Association des Physiologistes, Paris 5-6 octobre 1978.

Remerciements. - Nous remercions Mmes Alain et Quintana et M. Barry du Laboratoire de Biophysique dirigé par le Prof. Galle, de la Faculté de Médecine de Créteil, qui nous ont apporté leur concours dans l'utilisation de la microsonde électronique. 


\section{Références}

COLEMAN G. S., 1971. The cultivation of rumen Entodiniomorphid protozoa, 159-176. In SHAPTON D., BOARD R., Isolation of anaerobes, Coleman Acad. Press New-York.

FAILLA M. L., 1977. $\mathrm{Zn}$ : functions and transport in microorganisms. Microbiology ser. vol. 3, Microorganisms and minerals, 151-199. E. D. Weinberg, M. Delker Inc. NY.-Basel.

KUMARESAN A., 1976. Interactions entre le zinc et les microorganismes du rumen chez le mouton recevant de l'urée comme source unique d'azote. Thèse Doct. Univ., Toulouse.

UESAKA S., KAWASHIMA R., ZEMBAYASHI M., 1966. Effects of several mineral elements on the activity of volatile fatty acids production of rumen protozoa. Bull. Res. Inst. Food. Sci. Kyoto Univ., 29, 21-31. 